\title{
CULTURA CARMELITA EM AÇÃO: A CONSTRUÇÃO DA ORIGEM ELIANA DA ORDEM DE NOSSA SENHORA DO CARMO
}

André Cabral Honor ${ }^{1}$

Nas igrejas carmelitas é comum que seus altares-mores reservem espaço destacado para a imagem de Santo Elias. Ao lado da matrona da Ordem, Nossa Senhora do Carmo, o profeta do Antigo Testamento é a personagem mais representada dentro dos templos carmelitas que exaltam o profeta como fundador da Ordem de Nossa Senhora do Carmo. Enquanto que a incerteza sobre a origem do Carmelo pode ser vista como um demérito para a congregação, os carmelitas, por sua vez, souberam utilizar das dúvidas que pairam sobre sua fundação para elaborar um emaranhado de histórias que conduzem o profeta à origem do Carmelo, estabelecendo uma cultura história ${ }^{2}$ que põe a Ordem de Nossa Senhora do Carmo à frente das demais ordens ao se autodeclarar membro mais antigo do clero regular.

Formuladas em 1281 as Constituições Carmelitanas de Londres tentavam esclarecer dúvidas sobre a origem e desenvolvimento da Ordem de Nossa Senhora do Carmo, além de dispor sob os aspectos mais gerais da congregação. A sua rubrica I mencionava o profeta Elias na tentativa de elucidar os inúmeros questionamentos que surgiam sobre os primórdios da ordem. O excerto que se encontra transcrito em $\mathrm{Smet}^{3}$ e Bayón ${ }^{4}$, além de estar citado em Boaga ${ }^{5}$, expressa que desde os tempos do profeta Elias religiosos viviam no Monte Carmelo se dedicando à glória divina.

Não sabendo alguns irmãos, jovens na Ordem, dar uma resposta adequada aos que perguntam de quem e como é que a nossa Ordem teve o seu princípio, respondemos-lhes nós em sua vez, deixando-lhe uma forma por escrito. Dizemos, pois, em testemunho de verdade, que desde os

${ }^{1}$ Doutor em História pela Universidade Federal de Minas Gerais. Professor Adjunto do Departamento e do Programa de Pós-Graduação em História da Universidade de Brasília. E-Mail: <cabral.historia @gmail.com>.

${ }^{2}$ Para Joana Neves, cultura história é "a identidade social de uma dada comunidade, (parte e expressão social concreta de uma sociedade mais ampla) construída a partir do conhecimento histórico, considerado como algo que deve resultar em auto conhecimento da referida comunidade e dos indivíduos que a integram, fundamentados por uma visão crítica do processo histórico por meio do qual essa comunidade se constituiu e se situa na contemporaneidade. Acrescente-se a ainda que essa visão crítica deve ser assumida tanto por parte da comunidade como um todo como por seus integrantes, ou seja, os próprios agentes do processo histórico". NEVES, Joana. "Participação da Comunidade, Ensino de História e Cultura Histórica”. Saeculum - Revista de História, João Pessoa, n. 6/7, jan./dez. 2000/2001, p. 36.

${ }^{3}$ SMET, Joaquin O. Carm. Los Carmelitas: historia de la Orden Del Carmen - El Carmelo Español (Ca. 1260-1980). Tomo IV. Madri: Biblioteca de Autores Cristianos, 1993, p. 3-4.

${ }^{4}$ BAYÓN, Balbino Velasco O. Carm. História da Ordem do Carmo em Portugal. Tradução de Manuel R. Freitas. Lisboa: Paulinas, 2001, p. 18.

${ }^{5}$ BOAGA, Emanuele. Como piedras vivas... para leer la HISTORIA y la VIDA del CARMELO. Trad.ução de Juan Gil, Luis Ranz e Gaspar Mondéjar. Roma: Edizioni Carmelitane, 1997, p. 86. 
tempos dos profetas Elias e Eliseu, que viveram piedosamente no Monte Carmelo, alguns santos padres do Antigo Testamento, atraídos à solidão da mesma montanha para a contemplação das coisas celestiais, ali junto da fonte de Elias, perseveraram louvamente em santa penitência, acompanhada constantemente de actos de virtude. ${ }^{6}$

Os três historiadores são categóricos ao afirmar que foi a partir das interpretações desse excerto que se iniciou a legenda de Santo Elias como fundador dos carmelitas. Esse erro interpretativo constituiu a origem de uma problemática histórica para a Ordem de Nossa Senhora do Carmo.

Estas líneas, concisas y terminantes, en lugar de orientar, fueron simiente de gran confusión y de elucubraciones antihistóricas durante siglos; nos introducen también en el ambiente devocional al profeta Elías, propio de las comunidades carmelitas y evocan con añoranza el recuerdo de la montaña santa del Carmelo. ${ }^{7}$

Em 1725 o papa Benedito XII confirmava o profeta como fundador dos carmelitas por intermédio da autorização da instalação da escultura de Santo Elias na Praça de São Pedro no Vaticano, figurando-o entre os demais fundadores das ordens monásticas. Para que tal ação se concretizasse, houve um esforço nos bastidores do clero regular no que tange ao financiamento da escultura. As duas províncias carmelitas, Calçada e Descalça, ratearam os custos da obra em um raro momento em que agiram de comum acordo.

A origem eliana foi um dos tópicos mais polêmicos na História da Ordem de Nossa Senhora do Carmo. Defendida com ardor pelos carmelitas, por diversas vezes seria objeto de contestação por parte dos membros de outras congregações e clero regular.

O renomado padre jesuíta Daniel Van Papenbroeck, um dos editores da Acta Santorium, publicou em 1675, exatamente cinquenta anos antes da ereção da escultura do profeta na Praça de São Pedro, um texto que versava sobre a vida de Santo Alberto de Jerusalém. Considerado fundador da crítica documental moderna, o jesuíta contestou diversos textos canônicos, contestando fatos considerados históricos pela Igreja, chegando a declarar como fictícios diversos santos e santas venerados no século XVII.

La belleza y prestigio de tales orígenes se vino abajo a raíz de las investigaciones de los bolandistas en 1675. El serio Papebroke al tratar da vida de San Alberto demostró que el origen de los carmelitas no iba más allá de los fines del siglo

\footnotetext{
${ }^{6}$ BAYÓN, História da Ordem..., p. 17-18.

${ }^{7}$ SMET, Los Carmelitas..., p. 4.
} 

general. ${ }^{8}$

Os carmelitas se ofenderam com a afirmação de Daniel Van Papenbroeck denunciando-o ao Tribunal da Santa Inquisição que condenou os volumes da Actas Santorium. Contudo, essa sentença condenatória não foi confirmada pelo Vaticano, iniciando uma polêmica que envolveu as ordens seculares, o tribunal e o papado. $\mathrm{O}$ papa Inocêncio XII teve de intervir pessoalmente por meio de um decreto em que ordenava o imediato encerramento da discussão. Especula-se que o desfecho do caso só não foi prejudicial para o padre jesuíta porque ele gozava de grande prestígio dentro da Igreja. O padre Papenbroeck saiu praticamente ileso da contenda, porém desacreditado na questão que versava sobre a origem dos carmelitas.

Atualmente, os carmelitas atribuem a Santo Elias o título de pai da ordem, pois o profeta teria fornecido o modelo que inspirou a vida ascética dos primeiros eremitas do Monte Carmelo. Não obstante, esclarecem que Santo Elias não foi o fundador da Ordem de Nossa Senhora do Carmo no sentido literal da palavra como Santo Inácio havia sido dos Jesuítas ou São Francisco dos Seráficos, portanto, a suposta origem eliana dos carmelitas seria uma lenda de valor puramente espiritual.

Mesmo não existindo um estudo sobre o desmantelamento destas lendas [da Origem Eliana] em Portugal, pode afirmarse que o clima geral que se respira, actualmente, entre os carmelitas portugueses é similar ao de outras nações, isto é, dá-se a estas lendas o valor espiritual que têm, mas desvinculam-se, como é natural, da história, que vai por outros caminhos. ${ }^{9}$

Não obstante, no século XVIII a origem eliana não era questionada no universo cultural carmelita. Se na contemporaneidade a historiografia identifica São Brocardo como fundador, que aparece nos relatos com a simples alcunha de "B.", na Igreja Tridentina a situação era bem mais complexa. Mesmo admitindo Santo Elias como seu fundador, aceitava-se que a Ordem - baseada num modelo monástico estabelecido pela primeira vez por Bento de Núrsia ${ }^{10}$ - havia ressurgido com vigor por volta do século XII. Os carmelitas admitiam que a continuidade da congregação havia sido interrompida algumas vezes por guerras e invasóes à região do Monte Carmelo, o que explica o desaparecimento das casas conventuais que existiram anteriormente. Para justificar tal descontinuidade, os cronistas utilizavam de metáforas como as das fases da lua e a fênix mitológica.

\footnotetext{
${ }^{8}$ SEBASTIÁN, Santiago. Contrarreforma y barroco: lecturas iconográficas e iconológicas. 2 ed. Madri: Alianza, 1989, p. 240.

${ }^{9}$ BAYÓN, História da Ordem..., p. 19.

${ }^{10} \mathrm{O}$ fundador da primeira ordem religiosa nos moldes moderno foi Bento de Núrsia (São Bento) em 529 d.C.. Estabelecido na abadia de Montecassino, escreveu a Regra de São Bento, conjunto de normas que regeriam a vida religiosa naquele mosteiro. Infelizmente, o texto original de sua regra se perdeu sobrevivendo apenas traduções simplificadas.
} 
Muy acertado discurrió, quien comparó la Religión del Carmen al Fénix, pues renaciendo de sí misma, quando se ve más anciana, le imita en las propiedades. No le vale al fénix la variedad hermosa de sus plumas e lustrosas calidades, con que goza entre las demás aves la primacía, para que el tiempo no llegue a revolverla en cenizas; porque es peligrosa enfermedad, los muchos años. Pero es tal el cuidado de la sabia Providencia, que en estas mismas cenizas tiene su vida encerrada, y así cuando muere, renace, y quádo tiene más cerca el sepulcro, empieza à vivir de nuevo. ${ }^{11}$

A identificação de "B." como Brocardo também é uma convenção de historiadores carmelitas do século XX. À medida que se recua no tempo a história muda de personagem e outro monge aparece com maior destaque dentro da hagiografia. Incialmente, o frade "B." era identificado como São Bertholdo, um ex-cruzado, mais conhecido por ter sido o primeiro confessor geral da ordem e fundador da primeira casa do clero regular no Monte Carmelo. Os livros O jardim Carmelitano (1641) de frei Egidio Leoindelicato e Flores del Carmelo (1678) de frei Joseph de Santa Teresa corroboram com a asseveração de São Bertholdo como primeiro confessor geral da ordem e restaurador dos carmelitas, colocando essa informação no sumário de suas obras.

A crônica de frei Leoindelicato já indicava a posição a favor de São Bertholdo quando o coloca como primeiro geral latino da ordem carmelita e São Brocardo como o segundo. De acordo com frei Joseph de Santa Teresa, Bertholdo foi destinado à santidade antes do seu nascimento. $\mathrm{O}$ cronista carmelita narra que, certa noite, Guido de Malfayda sonhou com um anjo que lhe ordenava que abandonasse o monastério o qual havia adentrado poucos meses antes. Sem compreender o que the ocorria recorreu a São Gerardo ${ }^{12}$ que também havia tido o mesmo sonho indicando que Guido deveria deixar o convento. Aconselhou-o a voltar à sua terra, pois seria pai de dois varões que haveriam de ilustrar o oriente.

Mucho le suspendió esta voz, y sabiendo, que se transfigura en Ángel de luz el que es tinieblas, acudió a San Gerardo, a quien hallo orando en su Iglesia con otro capellán suyo, y le propuso, así la revelación, como sus dudas. El santo Obispo, que avía tenido el mismo aviso, le consoló, diciendo, no era voluntad de Dios que fuese Religioso, sino casado, porque

${ }^{11}$ TERESA, Joseph de Santa. Flores del Carmelo, vidas de los santos, de nuestra señora del Carmen, que reza su religion, assi em comum, como em particulares conventos. Madrid: Antonio Gonçalvez de Reyes, 1678, p. 153.

${ }^{12}$ Aqui se justifica a devoção carmelita a mais um santo que não pertencia à ordem, São Gerardo. "Se lo considera veneciano, nacido en el siglo X, perteneciente a la família Sagredi. Fue benedictino o canónico de San Marcos y obtuvo permiso para peregrinar a Tierra Santa. En el viaje pasó por Hungría y, como comprobara la necesidad de evangelizar a esos pueblos, quedó allí, y fue consagrado obispo de la diócesis de Csanad, donde murió mártir en 1046". SCHENONE, Héctor H. Iconografia del arte colonial. vol. 2. Buenos Aires: Tarea, 1992, p. 426. 
avía de ser Padre de dos lumbreras fulgentíssimas, que avían de ilustrar el Oriente [...]. ${ }^{13}$

A hagiografia de São Bertholdo resguarda muitas semelhanças com a narrativa apócrifa do nascimento do profeta Elias. O destino de São Bertholdo e Santo Elias havia sido revelado a seus pais durante o sonho, como podemos ler na hagiografia de Elias:

Nas vigílias do parto de sua ditosa mãy. A tempo, que elle já forcejava por se lhe desprender do escuro cárcere do ventre, sobreveyo a seu pay hum tão pesado somono, que por violento, e intempestivo, logo o reconheceu preternatural. Depois de adormecer vio claramente, que sua mulher paria hum hermosissimo, ao qual muitos Varões ornados de capas brancas com summa reverencia saudavão. Em vivas chamas lhe involviaõ o corpo e lhe davaõ a comer incendidas brasas: que pois a natureza do Infante era tão ardente, nem as mantilhas poderiaõ ser mais proporcionadas, nem mais competente a substancia do seu primeiro alimento. ${ }^{14}$

Essas semelhanças servem para estabelecer uma relação entre os "renascimentos" da ordem, já que os próprios carmelitas admitiam a descontinuidade temporal do Carmelo.

Guido de Malafaya obedeceu ao chamado, casou-se e teve dois filhos: Ademaro e Bertholdo. Ambos adotaram a vida espiritual e após a morte de seus pais abraçaram a causa da conquista da terra santa como determinada em 1095 pelo Papa Urbano II no Concílio de Clara-Monte. Quando se encontravam sitiados pelos Sarracenos na cidade da Antioquia, os dois cruzados rogaram a Deus pela salvação. Bertholdo prometeu a Nossa Senhora que caso se livrassem do cerco com a vitória da expedição ele tomaria o hábito do sagrado Monte Carmelo. Durante essa oração, o cruzado Bertholdo teve um visão de "Christo Senhor Nosso, com sua santissima Mãy, e o apostolo São Pedro, trazendo sobre a cabeça huma esplendida cruz" ${ }^{15}$. Lograda a conquista de seu pedido, o cruzado se dirigiu ao Carmelo tornando-se mais um eremita.

De acordo com frei Leoindelicato, Bertholdo percebeu os problemas que havia na falta de unidade entre os ermitões que usavam o hábito do Carmelo. Procurou uma solução que agregasse essas pessoas e restaurasse os costumes inspirados na vida do profeta Elias. Solicitou do Padre Aymérico, patriarca da Igreja da Antioquia, uma normativa escrita que pudesse ser aplicada àquele local. Em 1140 Aymérico de

\footnotetext{
${ }^{13}$ TERESA, Flores del Carmelo..., p. 154.

${ }^{14}$ ANNA, Joseph Pereira de Santa. Chronica dos carmelitas da antiga, e regular observância neste reynos de Portugal, Algarves, e seus Dominios. Tomo I. Lisboa: Officina dos Herdeiros de Antonio Pedrozo Galram, 1745, p. 5.

${ }^{15}$ LEOINDELICATO, Egidio. Jardim Carmelitano. Tradução de Frei Estevam de Santo Angelo. Terceira parte. Lisboa Occidental: Regia Oficina Sylviana, 1741, p. 3.
} 
Malafaia dirigiu-se ao Monte Carmelo e convidou os eremitas a se unirem em uma regra que professava obediência além de exigir a escolha de um superior geral para comandá-los. A escolha de Bertholdo como o primeiro geral marcou a fundação da primeira província carmelita que ainda passaria por inúmeros questionamentos sobre sua legitimidade. Após a morte de Bertholdo em 1187, Brocardo assumiu a província tornando-se o segundo geral da ordem. "Más el cielo los uniformo, y por común voto, y aclamación, San Brocado salió electo general, y fue el segundo de la Religión, en la cuenta del gobierno Latino"16.

Nas hagiografias, as histórias divergem apenas em pequenos detalhes narrativos, como o nome do irmão de Bertholdo que no livro de frei Joseph chama-se Aymerico, homônimo do patriarca da Antioquia. Trata-se do mesmo relato, porém narrado com maiores detalhes por frei Leoindelicato. Essa diferença advém da própria natureza dos escritos: enquanto Flores del Carmelo é um índice onomástico com a hagiografia dos principais santos carmelitas, Jardim Carmelitano se propõe a ser uma crônica com uma linha temporal linear centrando-se nas narrativas e personagens principais que formaram e expandiram a Ordem de Nossa Senhora do Carmo.

As visões celestiais tidas por personagens do universo católico faziam parte de uma concepção mística da doutrina. Vale ressaltar que as crônicas carmelitas levantadas não antecedem o século XVII, portanto, quando foram escritas, a Reforma Teresiana era uma realidade concreta ${ }^{17}$ e a mística religiosa já desaguava com mais força na Ordem Calçada com a Constituição da Estrita Observância de $1604^{18}$.

O misticismo era utilizado como ferramenta política para legitimar a guerra santa. Cristo e o Anjo Custódio de Portugal apareceram a D. Afonso Henriques garantindo sua vitória contra os muçulmanos na Batalha de Ourique em 25 de julho 1139, apesar da inferioridade numérica do exército do futuro monarca português. Durante a guerra de restauração, na batalha no Monte Tabocas na Capitania de Pernambuco

${ }^{16}$ TERESA, Flores del Carmelo..., p. 421.

17 "Em 1578, o Pe. Gerônimo Gracián reunia os Descalços em Almodóvar del Campo, e ali erigem sua província autônoma. Após muitas amarguras, foi aprovada a Reforma Teresiana pela Santa Sé em 1580 [...]". SCIADINI, Patrício. O Carmelo: História e espiritualidade. São Roque: Edições Carmelitanas, 1993, p. 55.

${ }^{18}$ A Constituição da Estrita Observância tem sua origem no Convento Carmelita Calçado de Turon na França que, no início do século XVII, iniciou um processo de reforma dos costumes, claramente inspirado na mística teresiana. Insatisfeito com o relaxamento dos costumes, alguns frades carmelitas formularam uma série de novas normas de convivência que foi sendo gradativamente absorvida pelos demais conventos da Província de Turon. O processo culminou na formulação de uma constituição (código de regras que rege uma ordem) a qual foi chamada de Estrita Observância ou Turônica. O sucesso da reforma fez com que esta constituição fosse adotada em outras províncias em detrimento da Constituição da Antiga Observância. Em claro movimento de impedir outra cisão dentro do Carmelo, como ocorreu com a fundação dos descalços, a Ordem Calçada de Nossa Senhora do Carmo passou a aceitar duas constituições (Estrita Observância, conhecida como Turônica e Antiga Observância, chamada de Observantes) deixando a cargo dos conventos a escolha da norma que os regeria. Sobre esse assunto ver: HONOR, André Cabral. "Origem e expansão no mundo luso da Observância de Rennes: a mística-militante dos carmelitas turônicos ou reformados no século XVII e XVIII". Clio: Série História do Nordeste, Recife, PPGH-UFPE, vol. 32, n. 1, abr./ ago. 2014, p. 215237. 
em 3 de agosto de 1645, Nossa Senhora e Santo Antão teriam intervido transformando areia em pólvora e assustando os holandeses com as suas aparições ${ }^{19}$.

Influenciados por este contexto, os livros ressaltam a ideia de uma intervenção divina direta no resultado das batalhas. Ao rogar pela salvação da sua vida, Bertholdo escutou de Cristo, que culpava a iminente derrota na batalha aos próprios pecados dos cristãos, a seguinte afirmação: "Vay, e dizes ao meu povo estas palavras, as vossas grandes maldades, e abusos, me faziaõ vos afastasse de mim, deixay de obrares mal, e me porey da volta parte para vos ajudar [...]"20. A crônica deixa claro que sem a intervenção divina a vitória não teria sido alcançada. Com a mesma espécie de intercessão Brocardo foi eleito e aclamado como segundo provincial da ordem.

Para os carmelitas, a vertente mística se encontrava diretamente atrelada a sua história. Em resposta aos que a acusavam de desestabilizar a província, Santa Teresa de Jesus, fundadora da Ordem Descalça de Nossa Senhora do Carmo, escreveu que seu desejo nada mais era do que restaurar os costumes de austeridade e devoção que haviam se diluído com o tempo. "No princípio de nossa Ordem, segundo me asseverou quem lhe conhece bem a história, a pobreza era tão estimada e praticada por nossos santos padres, que não guardavam coisa alguma de um dia para o outro" ${ }^{21}$. Apesar da cisão em duas ordens distintas, a fala da santa de Ávila indica que os carmelitas já possuíam em seu panteão de santos um modelo inspirador que andava de mãos dadas com o misticismo religioso e era parte intrínseca do Carmelo: o profeta Elias.

Em sua crônica, frei Joseph Pereira de Santa Anna expõe não só o ano de nascimento do profeta, mas também a data de criação do mundo.

Contavaõ-se tres mil setenta e tres annos da creaçaõ do mundo, que (conforme a computacaõ dos mais verídicos authores) vinhaõ a ser novecentos e oitenta annos antes do felice, e fausto nascimento de nosso amabilíssimo redemptor, quando na terra apareceo o inimitavel zelador da honra de Deos Santo Elias. ${ }^{22}$

Além dessa, as outras duas crônicas analisadas trazem uma datação para a criação do mundo e nascimento do profeta. O texto escrito por frei Joseph de Santa Teresa corrobora a datação colocada por frei Joseph Santa Anna, "corriendo los años de la creación del mundo tres mil e setenta e tres; y antes del nacimiento de Christo, noveciento y ochenta (según el compuso más verosímil) nació Elias [...]"23. Como a própria crônica expõe, não havia unanimidade entre os cronistas e historiadores carmelitas sobre a data de nascimento do profeta. Sobre esse tópico, frei Joseph

\footnotetext{
${ }^{19}$ Sobre as interferências dos santos nas guerras de restauração $e$ as mudança de identidade nas aparições ver o capítulo VII de: MELLO, Evaldo Cabral de. Rubro veio: o imaginário da restauração pernambucana. 3 ed. São Paulo: Alameda, 2008.

${ }^{20}$ LEOINDELICATO, Jardim Carmelitano, p. 3.

${ }^{21}$ JESUS, Teresa de. Caminho de perfeição. 10 ed. São Paulo: Paulus, 2008, p. 25.

${ }^{22}$ ANNA, Chronica dos carmelitas descalços..., p. 3.

${ }^{23}$ TERESA, Flores del Carmelo..., p. p. 365-366.
} 
Pereira de Santa Anna e frei Joseph de Santa Teresa expõem a mesma data, enquanto frei Belchior de Santa Anna apresenta uma datação diferente, "principiou nosso padre Elias sua Religião no Carmelo, por expresso mandado de Deos, em o anno de 3,1.2.4 da criação do mundo, 927 antes de Christo Senhor nosso nascer $[\ldots]]^{24}$.

Nos escritos judaicos extra-bíblicos que remontam aos primeiros dois séculos antes e depois de Cristo, E. [Elias] parece mais popular que Abraão ou Moisés. Evidenciam-se quatro as pectos da vida do profeta: seu arrebatamento ao céu, os milagres da sua vida 'terrena', a eficácia da sua oração $e$ a sua função de mestre, cujos discípulos são Eliseu $e$ Abdias. $^{25}$

O profeta Elias foi considerado pela Igreja como o primeiro eremita, aquele que teria estabelecido a tradição de padres que se isolavam em lugares inóspitos como desertos e montanhas. "Eventualmente aparece como figura paralela a João Batista, tanto mais que ambos não são só precursores de Cristo, mas também ascetas com a experiência do deserto" 26 . Os carmelitas apregoavam a figura do profeta como iniciador de uma linhagem de devotos que desejava viver de forma contemplativa, ou seja, com o mínimo de bens materiais possíveis e em total comunhão com a oração. Frei Joseph Santa Anna explica como foi construída essa relação entre o profeta Elias e São João Batista:

Afirmaõ que nascia para servir de modelo as virtudes ao Grande Bautista, crivel era, que assim sucedesse por havelo Deos prevenido da primeira graça santificante: e por este modo, naõ se acharia entre o Original, e a copia, alguma differença, visto que no espírito de Elias, e Bauttista tudo era semelhança. ${ }^{27}$

A sua analogia com João Batista também está explícita na Legenda Áurea, "[...] o que se aplica a João que veio com o espírito e a virtude de Elias" 28 . A origem dessa relação se baseia na passagem bíblica em que Pedro, Tiago e João questionam Cristo sobre a vinda de Elias, pois a volta do profeta deveria anteceder a chegada do messias. Da resposta de Cristo adveio a interpretação de que São João Batista seria o próprio profeta Elias.

${ }^{24}$ ANNA, Belchior de Santa. Chronica de carmelitas descalços particular do Reyno de Portugal e Provincia de Sam Felippe. Tomo I. Lisboa: Officina de Henrique Valente de Oliveira, 1657, p. 2.

${ }^{25}$ BORRIELlO, L. et al. (dir.). Dicionário de Mística. Tradução de Benoni Lemos et al. São Paulo: Paulus, 2003, p. 351.

${ }^{26}$ HEINZ-MOHR, Gerd. Dicionário dos símbolos: imagens e sinais da arte cristã. Tradução de João Rezende da Costa. São Paulo: Paulus, 1994, p. 142.

${ }^{27}$ ANNA, Chronica dos carmelitas descalços..., p. 6-7.

${ }^{28}$ VARAZZE, Jacopo de. A legenda áurea: vida de santos. Tradução de Hilário Franco Júnior. São Paulo: Schwarcz, 2003, p. 488. 
E perguntaram-lhe: "Porque motivo os escribas dizem que é preciso que Elias venha primeiro?" Ele respondeu: 'Elias certamente virá primeiro, para restaurar tudo. Mas como está escrito a respeito do Filho do Homem que deverá sofrer muito e ser desprezado? Eu, porém vos digo: Elias já veio, $e$ fizeram com ele tudo o que quiseram, como dele está escrito'. 29

A vida do profeta escrita pelo frei Joseph de Santa Teresa menciona a relação de Elias com São João Batista estabelecendo vínculos entre os dois personagens bíblicos.

Tal lo procurò parecer en sus primeros años; por lo qual afirman algunos Doctores, fue santificado en el vientre de su madre, y confirmado en gracia, como lo fue San Juan Bautista, pues vino en su espiritu, y virtud, y siendo sus nacimientos anunciados, y nacidos ambos para ser Virgines, Doctores, Martyres, Principes de el estado Monastico, y precursores de Christo, en una, y outra venida, verosimil es, que gozassen los dos unos mismos privilegios. ${ }^{30}$

A imagem de Elias não se encontra associada apenas a São João Batista, mas também ao próprio Cristo. As interpretações do texto bíblico apontam para uma correspondência entre as ações do profeta e Jesus, estabelecendo que Elias estava representando Cristo no Antigo Testamento. Frei Antonio Gonçalves expõe essa relação ao afirmar:

Helias, posto que a sagrada escritura nam ponha seu nascimento, nem o nome de seus paes, pera (segundo a glosa ordinária) sinificar o mysterio que representava, que he Christo Redemptor nosso: pero poem seu proprio nome, $q$ he Helias Thesbites, dos habitadores de Galaad. ${ }^{31}$

Tal associação eleva o profeta a um patamar único dentro da tradição católica. Assim como Moisés e Cristo, Elias veio para redenção dos homens e salvação do povo de Iahweh. Segundo frei Joseph de Santa Teresa o nome Elias foi posto por inspiração divina ou por ordem de um anjo, pois se tratava de um nome profético.

[...] pues se le impulso por alusion à las palabras, que dixo despues en el Carmelo: Dominus ipse est Deus. Y Elias quiere dezir em hebreo: El señor, u Dios del Señor, y en Griego Sol,

\footnotetext{
${ }^{29}$ MARCOS, Cap. 9, vers. 11-13. In: BÍBLIA de Jerusalém. 4 reimp. São Paulo: Paulus, 2006, p. 1772.

${ }^{30}$ TERESA, Flores del Carmelo..., p. 367.

${ }^{31}$ GONÇALVEZ, Antonio. Compendio das Chronicas da Ordem de Nossa Senhora do Carmo. S.l.: s.n., 1571, p. 51.
} 
y en una, y otra ethimolegia declararnos el Cielo su grandeza, y que tenía Elias tampoco de humanidad, que hasta el nombre era Celestial, y Divino. ${ }^{32}$

Profeta de ação ${ }^{33}$ que pregava o monoteísmo, não deixou nenhum registro escrito durante sua presença na terra. Na Bíblia há apenas a referência a uma carta enviada ao rei Jeorão ${ }^{34}$, escrita anos após o arrebatamento de Santo Elias aos céus. Cientes da importância do profeta para o cristianismo, os carmelitas insistiam no argumento de que ele era o fundador de fato da Ordem Primeira.

Ele é acima de tudo tipo de Cristo no antigo testamento. Viam-se paralelos com Cristo na semelhança da preparação para o seu ministério público, na luta pela pureza da doutrina contra os falsos ídolos, na cura de doentes e ressurreição de mortos, no combate em oração no deserto (corresponde ao Getsênami), e, enfim, na elevação aos céus. ${ }^{35}$

A passagem da transfiguração no novo testamento expõe a conexão entre Santo Elias e Cristo. Trata-se de um dos momentos mais importantes descritos na Bíblia, pois funciona como conexão entre o antigo e o novo testamento. O prestígio do profeta Elias nessa cena iguala-se ao de Moisés e do próprio Jesus Cristo, já que os três vieram ao mundo com a missão de reconduzir o povo para a verdadeira fé.

Seis dias depois, Jesus tomou Pedro, Tiago e seu irmão João, e os levou para um lugar à parte sobre uma alta montanha. E ali foi transfigurado diante deles. Seu rosto resplandeceu como o sol e as suas vestes tonaram-se alvas como a luz. E eis que lhes apareceram Moisés e Elias conversando com ele. Então Pedro, tomando a palavra, disse a Jesus: 'Senhor, é bom estarmos aqui. Se queres, levantarei aqui três tendas: um para ti, outra para Moisés e outra para Elias. Ainda falava, quando uma nuvem luminosa os cobriu como sua sombra e uma voz, que saía da nuvem, disse: "este é o meu Filho amado, em que me comprazo, ouvi-lo!" Os discípulos, ouvindo a voz, muito assustados, caíram com o rosto no

\footnotetext{
32 TERESA, Flores del Carmelo..., p. 367.

${ }^{33}$ Existem dois tipos de profetas na Bỉblia: os de ação, que atuam ativamente na conversão, e os profetas escritores, que se resumiram a escrever revelações e profecias.

34 "Chegou-lhe então um escrito do profeta Elias, que dizia: 'Assim fala Iahweh, o Deus de Davi, teu pai. Porque não seguiste o comportamento de Josafá, teu pai, nem o de Asa, rei de Judá, mas imitaste o exemplo dos reis Israel e és a causa da prostituição de Judá e dos habitantes de Jerusalém, como o foi a casa de Acab, e porque, além disso, mataste teus irmãos, tua família, que eram melhores do que tu, Iahweh vai ferir com um grande flagelo teu povo, teus filhos, tuas mulheres e todos os teus bens. Tu mesmo serás afligido por numerosas doenças, por uma moléstia nas entranhas de tal modo que, dia após dia, tuas entranhas sairão de teu corpo". 2 CRÔNICAS, Cap. 21, vers. 12-15. In: BÍBLIA de Jerusalém. 4 reimp. São Paulo: Paulus, 2006, p. 607.

${ }^{35}$ HEINZ-MOHR, Dicionário dos símbolos..., p. 142.
} 
chão. Jesus chegou perto deles e, tocando-os, disse: "Levantai-vos e não tenhais medo". Erguendo os olhos, não viram ninguém: Jesus estava sozinho. ${ }^{36}$

Tal relato se repete nos evangelhos de $\operatorname{Lucas}^{37}$ e $\operatorname{Marcos}^{38}$ com algumas pequenas variações. Comumente, inclusive nos estudos bíblicos atuais, associou-se o local da transubstanciação ao Monte Tabor, uma alta colina situada na Galiléia, "\& alcaçado no monte Thabor, em q asistio a Christo transfigurado" ${ }^{39}$. Todavia, alguns religiosos acreditavam que esse encontro teria ocorrido no Monte Carmelo lugar no qual Deus se revelou publicamente a pedido do profeta Elias. Independente do local onde ocorreu a transfiguração, a imagem de um monte está presente para relembrar o Sinai, lugar em que Deus se apresentou a Moisés.

Assim como a ordem está diretamente associada ao Carmelo, Elias também tem seu nome ligado ao monte. Nesse local o profeta realizou o milagre que o introduz na Bíblia como profeta de lahweh. A passagem no promontório existe para mostrar a superioridade do Deus de Elias sobre Baal ${ }^{40}$, divindade que era adorada pelo rei Acab e sua esposa Jezabel.

O Monte Carmelo é composto por uma cadeia de montanhas que se estendem por toda a península onde se encontra o Porto de Haifa no atual Estado de Israel.

Frecuentemente en las fuentes, y más todavia en la imaginación de aquellos que han oído hablar sin haberlo visto, el nombre del 'Monte Carmelo' evoca la última parte de un conjunto de montañas que constituyen una verdadera y auténtica cadena montañosa, en Tierra Santa. La cadena, de $25 \mathrm{~km}$ de larga por 12 de ancha, con una altura máxima de 546 metros, está surcada por un Valle y tiene una superficie de $150 \mathrm{~km}$ cuadrados. Limita por el norte con la Bahia de Haifa; por el sur con las tierras de Cesarea; al este con las llanuras de Esdrelón y Sarón; al oeste con el Mar Mediterráneo. El promontorio que se levanta sobre el Mediterráneo tiene una altitud de 150 metros y su anchura varía desde los 6 a los $8 \mathrm{~km}^{41}$

A história narrada no livro bíblico de 1 Reis, capítulo 18, inicia com um desafio proposto por Elias a Acab. O profeta pediu ao rei que convocasse o povo e os profetas de Baal para o Monte Carmelo. Quando todos se encontravam no

\footnotetext{
${ }^{36}$ MATEUS, Cap. 17, vers. 1-8. In: BÍBLIA de Jerusalém. 4 reimp. São Paulo: Paulus, 2006, p. 1735.

${ }^{37}$ LUCAS, Cap. 9, vers. 28-36. In: BÍBLIA de Jerusalém. 4 reimp. São Paulo: Paulus, 2006, p. 1805.

${ }^{38}$ MARCOS, Cap. 9, vers. 2-8. In: BíBLIA de Jerusalém. 4 reimp. São Paulo: Paulus, 2006, p. 1772.

${ }^{39}$ ANNA, Chronica de Carmelitas..., p. 3.

${ }^{40}$ De acordo com frei Joseph de Santa Teresa, Baal seria a personificação de Hércules. "Casado com gezabel, hija del rey de Tiro, que era gentil, admitió por dioses à sus Idolos, y hasta em su misma Corte, labró Templo à Hercules, à quien com nombre de Baal, adoravah Tyro. y Sidon, cabeças de la fenícia". TERESA, Flores del Carmelo..., p. 368.

${ }^{41}$ BOAGA, Como piedras vivas..., p. 29.
} 
promontório, Elias perguntou ao povo até quando eles seguiriam dois deuses. Diante da ausência de resposta sugeriu um desafio: ordenou que construíssem um altar, pusessem lenha ao redor e sobre as pedras colocassem um novilho esquartejado como sacrifício. Em seguida, pediu aos profetas de Baal que o invocassem. Se ele respondesse ao chamado, seria considerado o verdadeiro Deus. O povo concordou e dessa forma os profetas de Baal o fizeram. Durante uma manhã inteira clamaram por seu Deus, porém esse não apareceu. Após zombar dos profetas, Elias restaurou o altar de lahweh que havia sido destruído utilizando-se para esse fim doze pedras em uma clara alusão às tribos perdidas de Israel. Em cima do altar colocou lenha e ao seu redor cavou um fosso. Pediu para que enchessem quatro talhas de água $e$ despejassem sobre o holocausto $e$ o rego.

Na hora em que se apresenta a oferenda, Elias, o profeta, aproximou-se e disse: 'Iahweh, Deus de Abraão, de Isaac e de Israel, saiba-se que hoje tu és Deus em Israel, que sou teu servo e que foi por ordem tua que fiz todas estas coisas. Responde-me Iahweh, responde-me, para que este povo reconheça que és tu, Iahweh, o Deus, e que convertes os corações deles!' Então caiu o fogo de Iahweh e consumiu o holocausto e a lenha, e as pedras e a terra, secando a água que estava no rego. Todo o povo o presenciou; prostrou-se com o rosto em terra, exclamando: 'É Iahweh que é Deus! É Iahweh que é Deus! ${ }^{\prime 42}$

Após a aclamação do povo, Elias obrigou os quatrocentos e cinquenta profetas de Baal a descerem para perto da torrente do Quison onde os degolou. Em seguida, ordenou que Acab voltasse para seu palácio, pois a chuva que iria acabar com a seca que ele mesmo profetizara há três anos estava por vir. Elias subiu ao alto do monte Carmelo, prostrou-se e mandou que o servo que lhe acompanhava olhasse sete vezes em direção ao mar. Na sétima vez o discípulo viu uma nuvem subindo da água salobra trazendo a chuva de volta à região.

Dentro da tradição literária carmelita essa cena também pode ser interpretada como uma passagem que une a devoção mariana da ordem a Elias, justificando sua alcunha de fundador. A nuvem carregada de água que acabou com a seca na região seria a própria virgem Maria com seu filho concebido no ventre.

Nam he isto meu: mas do sancto póntifice Medionalnenfe Ambrosio declarando aquelle passo de Esaias em que diz. $O$ senhor assentando sobre a nuvem leve vem a egipto que significa a aflição deste misero mundo, ao qual vem Deos pela virgem significada pela nuvem, e era leve porque era virgem sem alguma carga de corrupção. O bem aventurado Sam Crisostomo declarando o mesmo lugar, entende por esta nuvem a carne que Christo recebeu no ventre virginal da

\footnotetext{
421 REIS, Cap. 18, vers. 36-39. In: BÍBLIA de Jerusalém. 4 reimp. São Paulo: Paulus, 2006, p. 498.
} 
gloriosa padroeira nossa, e ally o entende nicholao de lira. [...] O docissimo Sam Jeronimo expondo o mesmo lugar de esaias diz. a nuvem leve, he o corpo da virgem gloriosa [...]. ${ }^{43}$

O profeta Elias era a personagem que fazia o vínculo entre os eremitas do Monte Carmelo e a mãe de Jesus. O milagre da fértil chuva trouxe a virgem para o promontório pela primeira vez.

Historiadores carmelitas de renome, como Joaquin Smet, Emanuele Boaga e Balbino Bayón iniciam a História da Ordem a partir do século XIII, porém retomam o mito da origem eliana para justificar a presença do profeta dentro dos templos carmelitas.

\begin{abstract}
Se trata de un vínculo que lleva a mirar al gran profeta como maestro, prototipo o modelo inspirador en la línea de la tradición patrístico-monástica. Esta tradición se entrelaza con la haggadah eliana en la tradición rabínica-hebrea y en los desarrollos realizados por los padres sírios, griegos, latinos y en los bizantinos. Esta haggadah Eliana ya en los siglos IV-V llevaba a ver en Elías profeta tipo-padre de la vida ascética y monástica. $^{44}$
\end{abstract}

No século XVII a presença do profeta Elias como fundador dos carmelitas toma contornos ainda maiores, pelo menos para parte as casas conventuais que adotaram a Constituição da Estrita Observância ${ }^{45}$. Para os carmelitas turônicos, a presença do profeta no universo cultural carmelita, além de colocar uma figura bíblica de suma importância para o cristianismo como fundador da ordem religiosa, também servia de base para a presença do misticismo na Ordem de Nossa Senhora do Carmo. Antes mesmo da reforma de Santa Teresa d'Ávila, Santo Elias já trazia para os carmelitas a mística religiosa. Toda a narrativa da vida do profeta na Igreja de Nossa Senhora do Carmo do Recife é conduzida nessa relação direta com Deus.

O ciclo bíblico do profeta possui como foco principal o embate na dicotomia lahweh e Baal que simbolizam vida e morte, respectivamente.

Essa conclusão é sugerida a partir destes dados literários: a. o uso abundante da fórmula de juramento "Pela vida do Senhor teu Deus..." (1Rs 17,1.12; 18,10.15; 2Rs 2,2.4.6). Nos escritos deuteronomistas, dos quais faz parte também o ciclo de E., essa expressão é empregada quase exclusivamente quando se trata da vida ou da morte de alguém; $b$. o emprego freqüente dos verbos e dos nomes que denotam as atividades e os elementos necessários para a

\footnotetext{
${ }^{43}$ GONÇALVEZ, Compendio das Chronicas, p. 57.

${ }^{44}$ BOAGA, Como piedras vivas..., p. 83.

${ }^{45} \mathrm{Na}$ América portuguesa, a Constituição da Estrita Observância ou Turônica foi adotada pelos conventos do Recife, Goiana e Cidade da Paraíba no final do século XVII.
} 
preservação da vida humana: alimentar-se e prover o sustento (cf. 1Rs 17,4.9.12; 18,13; 19,5.6.7.8); beber (cf. 1Rs 17,4.6.10; 19,6); chuva (cf. 1Rs 17,1.7.14; 18,1.41.44.45); água (cf. 17,10; 18,4.13); óleo(cf. 17,12.14.16); pão/ fogaça (cf. 1Rs 17,6.11.13; 18,4.13; 19,6); e carne (cf. 1Rs 17,6); cf. $o$ uso freqüente dos diversos verbos que significam o ato de matar (cf. 1Rs 17,18.20; 18,4.12.13.14.40). ${ }^{46}$

Elias experimentou Deus em sua vida sem a presença de intermediários na relação. Se a vivência mística, seja de qual religião for, tem como base essa vivência do amor divino em vida, o profeta foi testemunha da presença de Deus e do contato direto da divindade com o humano, "porque sempre e em todo lugar contempla e experimenta a presença e a força vivificante do Deus de Israel" ${ }^{47}$. Mais do que perceber a presença do onipresente, ele comungou com o mesmo tornando-se seu instrumento de ação. Atestou a presença de Deus tornando-o manifesto, relação que permeia todo o ciclo bíblico de Santo Elias com destaque para as passagens que narram o milagre no monte Carmelo $e$ o arrebatamento aos céus numa carruagem de fogo. Para os carmelitas turônicos, a imagem do profeta adquiria significados ainda maiores: seu modelo de vida justificava o misticismo como motor da vida missionária na América portuguesa.

\footnotetext{
${ }^{46}$ BORRIELLO et al., Dicionário de Mística, p. 350.

${ }^{47}$ BORRIELLO et al., Dicionário de Mística, p. 351.
} 


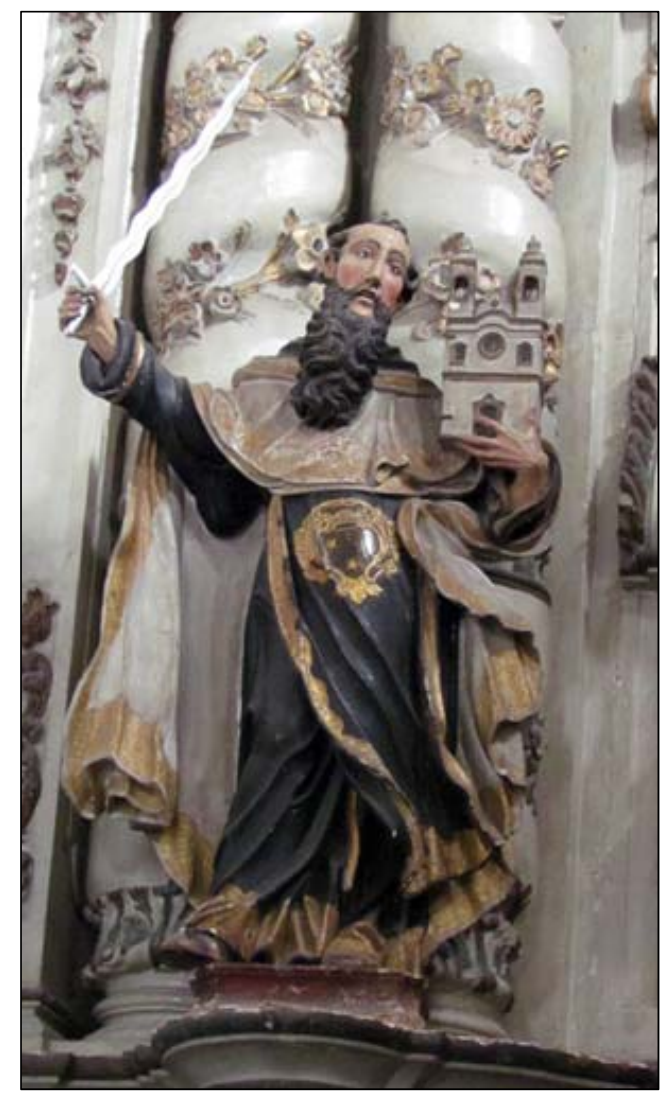

Fig. 1 - Santo Elias, imaginária barroca, autoria anônima, segunda metade do século XVIII. Madeira policromada e dourada, com olhos de vidro, c. $100 \mathrm{~cm}$ de altura. Igreja da Ordem Primeira de Nossa Senhora do Carmo, João Pessoa, Paraíba. Foto: acervo do autor, 20 jul. 2008.

Fig. 2 - Santo Elias, imaginária barroca, autoria anônima, segunda metade do século XVIII. Madeira com esgrafito, policromada e dourada, com olhos de vidro, c. $90 \mathrm{~cm}$ de altura. Igreja da Ordem Primeira de Nossa Senhora do Carmo, Recife, Pernambuco. Foto: acervo do autor, 30 jul. 2012.

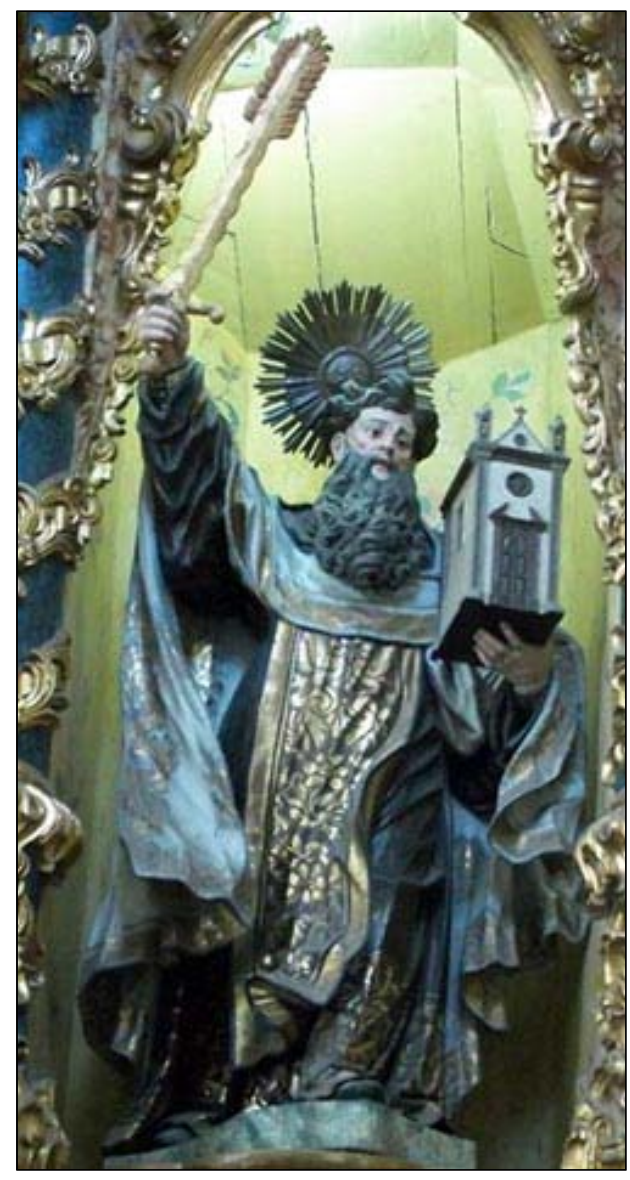


Nos templos pertencentes aos reformados nas capitanias do norte, o profeta é representado segurando uma igreja nas mãos (Figs. 1, 2, 3 e 4) em consonância com a sua caracterização nas crônicas como fundador da ordem. Além da espada flamejante, referência à morte dos 450 profetas de Baal ao pé do Monte Carmelo, as imagens de Santo Elias possuem outras características em comum: vestem uma capa branca, portam o escapulário, possuem uma barba comprida e usam uma tonsura. No título do primeiro capítulo de sua crônica frei Joseph Pereira de Santa Anna ${ }^{48}$ escreve "Da gloriosa Patria, authorizados progenitores, e fausto nascimento do grande Proto-Patriarca Elias" ${ }^{\text {". }}$. Em Flores do Carmelo, o título que introduz o capítulo sobre a hagiografia do profeta diz "Via de nuestro padre, Fundador y Patriarca de la Religion Carmelita" 50 .

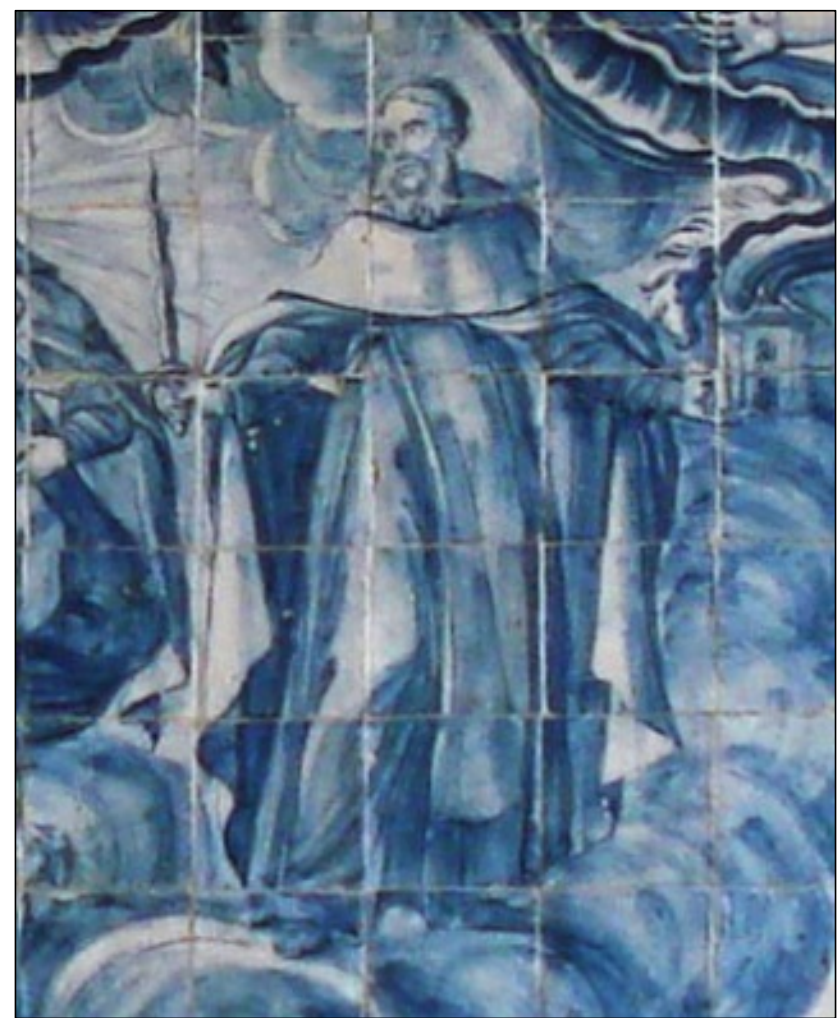

Fig. 3 - Santo Elias, azulejaria portuguesa, autoria anônima, segunda metade do século XVIII. Igreja da Ordem Primeira de Nossa Senhora do Carmo, João Pessoa, Paraíba. Foto: acervo do autor, 20 jul. 2008.

\footnotetext{
${ }^{48}$ Foi localizada uma cópia desta crônica no Convento Carmelita do Recife.

${ }^{49}$ ANNA, Chronica dos carmelitas da antiga..., p. 1.

${ }^{50}$ TERESA, Flores del Carmelo..., p. 365.
} 


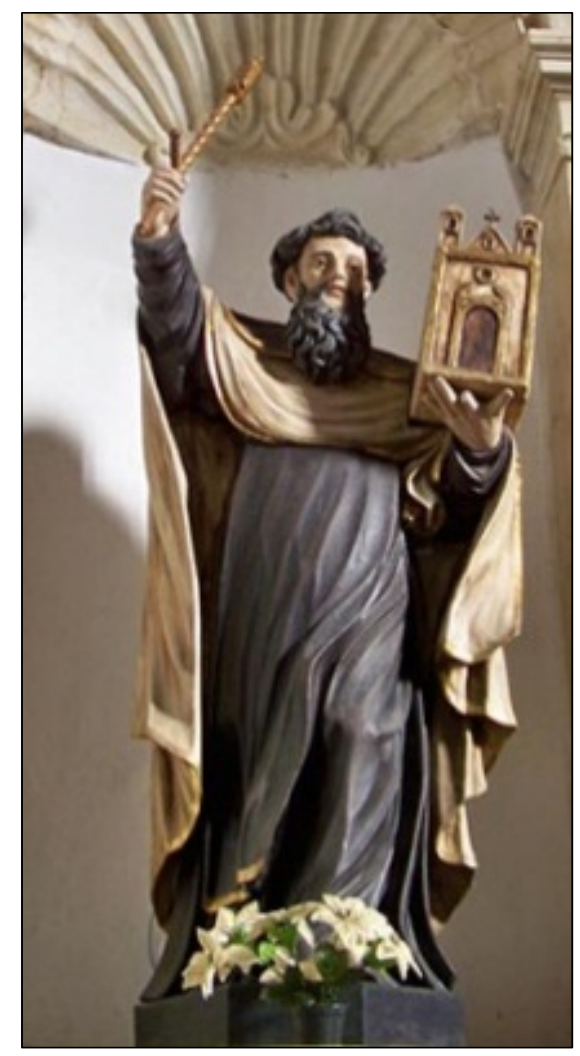

Fig. 4 - Santo Elias, imaginária barroca, autoria anônima, final do século XVIII, começos do século XIX. Madeira policromada, com olhos de vidro, c. $80 \mathrm{~cm}$ de altura. Igreja de Nossa Senhora da Guia, Lucena, Paraíba. Foto: acervo do autor, 13 jan. 2012.

O ciclo de Elias na Bíblia inicia-se com sua primeira aparição quando profetiza a seca no reino de Acab, "Pela vida de Iahweh, o Deus de Israel, a quem sirvo: não haverá nestes anos nem orvalho nem chuva, a não ser quando eu o ordenar" ${ }^{\prime 51}$. Todavia, existia uma tradição de legendas hagiográficas que narravam a vida do profeta desde o seu nascimento ressaltando o viés místico. Alguns cronistas incorporaram essa legenda aos seus escritos, porém outros preferiram se ater ao relato bíblico. Frei Antonio Gonçalves, por exemplo, apesar do seu preciosismo em precisar as localizações geográficas dos lugares citados como uma forma de dar veracidade ao seu discurso, optou por descrever apenas os relatos bíblicos iniciando a história de Elias com a profetização da seca no reino de Acab, concentrando-se nas experiências místicas bíblicas.

Ao narrar o milagre no Monte Carmelo, as crônicas carmelitas vão além da conexão do profeta com o promontório: elas articulam sua hagiografia com a vinda da matrona da Ordem para a terra. Dessa maneira, Elias torna-se o fundador de fato da congregação ao iniciar a devoção à Nossa Senhora do Carmo. As crônicas carmelitas, ao mesmo tempo que são fruto da cultura histórica da ordem, também são fatores de transformação dessa cultura, ao incluírem ou obliterarem elementos que variam de acordo com os desafios enfrentados. Assim, constroem uma narrativa que declara a primazia da Ordem Carmelita perante as demais, proporcionando à

51 REIS, Cap. 17, vers. 1. In: BÍBLIA de Jerusalém. 4 reimp. São Paulo: Paulus, 2006, p. 495.

SAECUluM - ReVista de História [37]; João Pessoa, jul./ dez. 2017. 
congregação uma antiguidade única ao inserir na fundação do Carmelo o profeta Elias, um dos pilares do catolicismo. Dessa maneira, a Ordem de Nossa Senhora do Carmo fez uso de sua cultura histórica para se legitimar perante a sociedade e, principalmente, diante da Igreja Católica, instituição à qual se encontrava inexoravelmente conectada em uma relação que estava longe de ser estável.

\section{$\operatorname{son} 2$}

\section{RESUMO}

O presente artigo busca analisar a origem eliana da Ordem Primeira de Nossa Senhora do Carmo através da perspectiva da História Cultural, formulando-se, para isso, o conceito de cultura histórica carmelita. A análise utilizou como fontes primárias as principais crônicas carmelitas que narram a história da Ordem, que sempre principiam com a presença do profeta Elias na Terra, seja narrando sua história desde o seu nascimento ou tomando como ponto de partida o seu ciclo bíblico. Fruto de extrema controvérsia, a origem eliana possui papel fundamental dentro da Ordem Carmelita ao proporcionar à congregação a primazia da antiguidade entre o clero regular conectando a presença do profeta no Monte Carmelo ao surgimento da devoção à Nossa Senhora do Carmo.

Palavras Chave: Carmelitas; Hagiografia; Fundador; Santo Elias.

Artigo recebido em 04 ago. 2017.

Aprovado em 13 set. 2017.

\begin{abstract}
This article analyses the connections between the prophet Elijah and the origin of the First Order of Our Lady of Carmel based on the perspective of Cultural History, and introducing the concept of Carmelite historical culture. The analyses used, as primary sources, the most important Carmelite chronicles which narrate the history of the Order and always begin with the presence of the Prophet Elijah on Earth. Despite all the controversy, Elijah's origin plays a fundamental role within the Carmelite Order by providing the congregation with the primacy of antiquity among the regular clergy, connecting the presence of the prophet on Mount Carmel to the rise of devotion to Our Lady of Carmel.
\end{abstract}

Keywords: Carmelites; Hagiography; Founder; Saint Elijah, 